Revista Brasileira de Agricultura Irrigada v.13, no .4, p. 3556 - 3567, 2019

ISSN 1982-7679 (On-line)

Fortaleza, CE, INOVAGRI - http://www.inovagri.org.br

DOI: $10.7127 /$ rbai.v13n4001081

Protocolo 1081.19-09/04/2019 Aprovado em 09/12/2019

\title{
EMERGÊNCIA E CRESCIMENTO DE PLÂNTULAS DE FEIJÃO-CAUPI EM SUBSTRATOS IRRIGADAS COM ÁGUA SALINA
}

Antônio Welder Freire de Oliveira ${ }^{1}$, Virna Braga Marques ${ }^{2}$, Francisco Barroso da Silva Junior ${ }^{3}$, José Marcelo da Silva Guilherme 3 , Andreza Silva Barbosa ${ }^{3}$, Geocleber Gomes de Sousa ${ }^{4}$

\section{RESUMO}

O uso de substratos alternativos (esterco bovino, biocarvão, casca de arroz carbonizada) atenua o estresse salino na cultura do feijão. Visto isso, objetivou-se avaliar o efeito da água salina versus diferentes substratos na emergência e crescimento inicial do feijão-caupi BRS Tumucumaque. O experimento foi conduzido no delineamento inteiramente casualizado em esquema fatorial $2 \times 3$, correspondente a dois níveis de condutividade elétrica da água - CEa $\left(0,8\right.$ e 4,0 dS m $\left.\mathrm{m}^{-1}\right)$, e três substratos, S1: areia + arisco + esterco bovino (1:1:1); S2: areia + arisco + biocarvão (1:1:1); e S3: areia + risco + casca de arroz carbonizada (1:1:1), em quarto repetições com 25 sementes. As variáveis analisadas foram: porcentagem de emergência (PE), índice de velocidade de emergência (IVE), tempo médio de emergência (TME), velocidade média de emergência (VME), altura da planta (AP), comprimento da raiz (CR), massa seca da parte aérea (MSPA), e massa seca da raiz (MSR). A cultivar BRS Tumucumaque avaliada apresentou baixa tolerância a salinidade em $4 \mathrm{dS} \mathrm{m}^{-1}$, apresentando limitações no seu desenvolvimento inicial. As plântulas apresentaram melhor desenvolvimento no substrato com adição de esterco bovino, demostrando melhor eficiência para o desenvolvimento da cultivar avaliada nas variáveis altura da plântula, comprimento da raiz, massa seca da parte aérea e massa seca da raiz.

Palavras-chave: Vigna unguiculata (L.) walp, sementes, estresse salino.

\section{EMERGENCY AND GROWTH OF CAUPI BEAN IN SUBSTRATES IRRIGATED WITH SALINE WATER ABSTRACT}

\footnotetext{
${ }^{1}$ Engenheiro Agrônomo, Universidade da Integração Internacional da Lusofonia Afro-Brasileira, Redenção, CE, Brasil, e-mail: welder2728@gmail.com

${ }^{2}$ Profa. Dr., Instituto de Desenvolvimento Rural, Universidade da Integração Internacional da Lusofonia Afro-Brasileira, Redenção, CE, Brasil, e-mail: virna@unilab.edu.br

3 Graduandos em Agronomia, Instituto de Desenvolvimento Rural, Universidade da Integração Internacional da Lusofonia Afro-Brasileira, Redenção, CE, Brasil, e-mail: juniorbarroso_99@hotmail.com; jose.marcelosilva98@gmail.com; andrezabarbosaunilab@gmail.com

${ }^{4}$ Prof. Dr., Bolsista de Produtividade da FUNCAP, Instituto de Desenvolvimento Rural, Universidade da Integração Internacional da Lusofonia Afro-Brasileira, Redenção, CE, Brasil, e-mail: sousagg@unilab.edu.br
} 
The use of alternative substrates (cattle manure, biocarbon, charcoal rice husk) attenuates saline stress in bean culture. Seen this, the objective of this work was to evaluate the effect of saline water on different substrates in the emergence and initial growth of cowpea BRS Tumucumaque. The experiment was conducted in a completely randomized design in a $2 \times 3$ factorial scheme, corresponding to two levels of electrical conductivity of water - CEa $\left(0.8\right.$ and $\left.4.0 \mathrm{dS} \mathrm{m}^{-1}\right)$, and three substrates, , S1 = sand + arisco + bovine manure (1:1:1); S2 = sand + arisco+ biochar (1:1:1); and $\mathrm{S} 3=$ sand + arisco + carbonized rice hull $(1: 1: 1)$, in four replicates with 25 seeds. The analyzed variables were: emergency percentage (EP), emergency speed index (ESI), average time of emergency (MET), average speed of emergency (EMV), plant height (PH), root length (RL), dry mass of the aerial part (DMAP), and root dry mass (DRM). The cultivar BRS Tumucumaque evaluated showed low tolerance to salinity in $4 \mathrm{dS} \mathrm{m} \mathrm{m}^{-1}$, presenting limitations in its initial development. The seedlings presented better development in the substrate with addition of bovine manure, demonstrating better efficiency for the development of the cultivar evaluated in the variable's height of the seedling root length, dry mass of the aerial part and dry root mass.

Keywords: Vigna unguiculata (L.) walp, seeds, saline stress.

\section{INTRODUÇÃO}

O feijão caupi é considerado uma cultura de subsistência, principalmente por ser produzido por pequenos agricultores da região do semiárido nordestino apenas em estações chuvosas (SILVA et al., 2009). Sem acesso a tecnologia de irrigação, o agricultor fica incapaz de aumentar sua produção de alimentos fora dos períodos de chuvas.

Entretanto, ao usar esta tecnologia se deve ter alguns cuidados em seu manejo, pois o mal-uso desta pode acarretar em problemas como a salinização dos solos, ou seja, ter efeito oposto ao aumento da produção de alimentos. Silva et al. (2013) cita que as condições do Nordeste no que se refere ao clima pelo fato de apresentar altas temperaturas e pluviosidade relativamente baixas são fatores que vem causando salinização nos solos da região. As regiões áridas e semiáridas são caracterizadas pela baixa pluviosidade e alta demanda evaporativa, o que torna esses locais susceptíveis à salinização do solo trazendo prejuízos à agricultura (LEITE et al., 2017).

Deste modo, a salinização afeta aspectos das plantas de modo que modifica as estruturas tanto metabólicas como morfológicas da cultura, causando redução na germinação e emergência das sementes. O estádio inicial da cultura, como a emergência, seu desenvolvimento e sua produção são afetados tanto pela quantidade de sais em suas estruturas causando toxidez, como pela dificuldade de absorção da água pelo sistema radicular em consequência da presença dos sais. Lopes e Macedo, (2008) relatam que os sais interferem no potencial hídrico do solo, causando no gradiente potencial redução entre o solo e a superfície da semente que diminui a absorção de água por ela.

Desta forma, os substratos a ser utilizados para a semeadura, deve-se levar em conta a estrutura física, componentes químicos, biológicos e nutricional para um bom desenvolvimento da cultura desde a sua germinação. Para se ter um bom substrato para formação e produção de mudas ele deve apresentar certas características, tais como: disponibilidade de aquisição na região, facilidade no transporte, baixo custo, ausência de patógenos, riqueza de nutrientes e condições adequadas ao crescimento da planta (SILVA et al., 2001).

A casca de arroz por sua vez, como complemento para substrato, quando carbonizada, apresenta alta capacidade de drenagem, fácil manuseio, peso reduzido, $\mathrm{pH}$ levemente alcalino, forma floculada, livre de patógenos e nematóides, teor adequado de $\mathrm{Ke}$ $\mathrm{Ca}$ que são dois macronutrientes essenciais para o desenvolvimento vegetal (SAIDELLES et al., 2009). 


\section{EMERGÊNCIA E CRESCIMENTO DE PLÂNTULAS DE FEIJÃO-CAUPI EM SUBSTRATOS IRRIGADAS} COM ÁGUA SALINA

Já o biocarvão de acordo com Van Zwieten et al. (2010) pode modificar o $\mathrm{pH}$ do solo por apresentar teores de nutrientes como o $\mathrm{Mg}$ e conter $\mathrm{CaCO}_{3}$. Além de outros nutrientes essenciais às plantas, como $\mathrm{K}$ e $\mathrm{P}$, e micronutrientes como o $\mathrm{Mn}, \mathrm{Fe}, \mathrm{Cu}, \mathrm{Zn}, \mathrm{Mo}$ (NOVAK et al., 2009; GRABER et al., 2010), deste modo, favorecendo a permanência de nutriente no solo.

Quanto ao esterco bovino pode proporcionar a troca de cátion, além da capacidade de retenção e infiltração de água, melhorar a porosidade e a temperatura do solo. Proporcionando acúmulo de nitrogênio orgânico, auxiliando no aumento do seu potencial de mineralização de disponibilidade de nutriente para as plantas (TEJADA et al., 2008).

Dado o exposto, o trabalho teve como objetivo avaliar o efeito da água de baixa e alta salinidade de irrigação na emergência e crescimento inicial do feijão-caupi BRS Tumucumaque, com desenvolvimento em substratos contendo concentrações de esterco bovino, biocarvão e casca de arroz carbonizada.

\section{MATERIAIS E MÉTODOS}

O experimento foi conduzido na Unidade de Produção de Mudas Auroras (UPMA), no Campus dos Auroras, da Universidade da Integração Internacional da Lusofonia Afro-Brasileira (UNILAB), localizada no município de Redenção-CE, com latitude $4^{\circ} 13^{\prime} 33^{\prime \prime} \mathrm{S}$, longitude $38^{\circ} 43^{\prime}$ $50 " \mathrm{~W}$ e altitude $88,8 \mathrm{~m}$. Essa região caracteriza-se por apresentar uma temperatura média anual de $26^{\circ} \mathrm{C}$ a $28^{\circ} \mathrm{C}$, pluviosidade média de $1.062 \mathrm{~mm}$ e estação chuvosa de janeiro a abril (IPECE, 2017).

Para a condução do experimento, foram utilizadas sementes do feijão-caupi BRS Tumucumaque (Vigna unguiculata L., Walp). As sementes foram semeadas em bandejas de isopor contendo substratos com as características químicas descritas na (Tabela 1) e irrigadas diariamente duas vezes ao dia.

Tabela 1. Características químicas dos componentes dos substratos utilizados na germinação de feijão-caupi BRS Tumucumaque.

\begin{tabular}{|c|c|c|c|c|c|c|c|c|c|c|c|c|c|c|}
\hline Sub. & $\mathrm{Ca}^{2+}$ & $\mathrm{Mg}^{2+}$ & $\mathrm{Na}^{+}$ & $\mathrm{K}^{+}$ & $\mathrm{V}$ & M & PST & $\mathrm{C}$ & $\mathrm{N}$ & M O & $\mathrm{C} / \mathrm{N}$ & $\mathrm{P}$ & $\begin{array}{c}\mathrm{pH} \\
\text { (Água) }\end{array}$ & $\mathrm{CE}$ \\
\hline \multicolumn{5}{|c|}{---- $\left(\mathrm{cmolc} \mathrm{kg}^{-1}\right)$----- } & \multicolumn{3}{|c|}{---- (\%) ---- } & \multicolumn{3}{|c|}{----- $\left(\mathrm{g} \mathrm{kg}^{-1}\right)$------ } & - & \multicolumn{2}{|c|}{$\left(\mathrm{mg} \mathrm{kg}^{-1}\right)$} & $\left(\mathrm{dS} \mathrm{m}{ }^{-1}\right)$ \\
\hline EB & 4,9 & 0,9 & 0,26 & 0,58 & 95 & 0 & 4 & 8,55 & 0,93 & 14,74 & 9 & 20 & 7,4 & 1,34 \\
\hline $\mathrm{BC}$ & 0,6 & 0,4 & 0,1 & 0,16 & 88 & 0 & 7 & 2,36 & 0,24 & 4,07 & 10 & 10 & 7,2 & 0,48 \\
\hline CAC & 0,7 & 0,5 & 0,08 & 0,24 & 75 & 3 & 4 & 3,01 & 0,31 & 5,18 & 10 & 20 & 6,9 & 0,61 \\
\hline
\end{tabular}

Sub.: Substratos EB: areia, arisco e esterco bovino; BC: areia, arisco e biocarvão; CAC: areia, arisco e casca de arroz carbonizada, com proporções de (1:1:1) para ambos os substratos.

A quantidade de sais cloreto de sódio $(\mathrm{NaCl})$, cálcio $\left(\mathrm{CaCl}_{2} \cdot 2 \mathrm{H}_{2} \mathrm{O}\right)$ e magnésio $\left(\mathrm{MgCl}_{2 .} 6 \mathrm{H}_{2} \mathrm{O}\right)$ utilizados no experimento para o preparo da água de irrigação foram de acordo com a proporção de 7:2:1 seguindo a relação entre condutividade elétrica da água $\mathrm{CEa}$ e sua concentração $\left(\mathrm{mmol}_{\mathrm{c}} \mathrm{L}^{-1}=\mathrm{CE} \mathrm{x}\right.$ $10)$, conforme proposto por Rhoades et al. (2000).

O experimento foi conduzido com delineamento inteiramente casualizado (DIC) em esquema fatorial $2 \times 3$ com 4 repetições, no qual o primeiro fator corresponde a dois níveis de condutividade elétrica da água - CEa: 0,8 e 4,0 dS m$~^{-1}$ e o segundo fator a três substratos: S1: areia + arisco + esterco bovino (1:1:1), S2: areia + arisco + biocarvão (1:1:1) e S3: areia + risco + casca de arroz carbonizada (1:1:1).

Durante o período experimental para a obtenção da porcentagem de emergência (PE), foram feitas contagens diárias das sementes emergidas sendo realizadas as 09:00 hs, com 
dados obtidos de acordo com cálculos de Labouriau e Valadares (1976).

Para as variáveis de índice de velocidade de emergência (IVE) e o tempo médio de emergência (TME) foram consideradas emergidas as sementes com os cotilédones expostos até o $9^{\circ}$ dia após a semeadura, com dados calculados pelas fórmulas proposta por (MAGUIRE, 1962; NAKAGAWA, 1999). A velocidade média de emergência (VME) foi obtida pela divisão de 1 pelo valor do tempo médio de emergência.

Aos nove dias após a semeadura (DAS) as plântulas foram coletadas e medidas a altura (AP) e o comprimento da raiz (CR) com auxílio de régua graduada. Em seguida foram acondicionadas em sacos de papel e colocadas para secar dentro da Unidade de Produção de Mudas Auroras (UPMA) durante 12 dias, posteriormente o material foi pesado em balança de precisão para obter o peso seco, massa seca da parte aérea (MSPA) e massa seca da raiz (MSR).

$\mathrm{O}$ teste de Kolmogorov-Smirnov $(p<0,05)$ foi aplicado à normalidade para variáveis: porcentagem de emergência (PE), índice de velocidade de emergência (IVE), tempo médio de emergência (TME), velocidade média de emergência (VME), altura da planta (AP), comprimento da raiz
(CR), massa seca da parte aérea (MSPA), e massa seca da raiz (MSR), sendo observada distribuição normal $(p<0,05)$. Os dados em seguida foram submetidos a análise de variância, pelo teste $\mathrm{F}(\mathrm{p}<0,05)$ e após verificar significância foi realizado o teste de comparação de média de Tukey $(\mathrm{p}<0,05)$, utilizando o programa ASSISTAT 7.7 BETA (SILVA; AZEVEDO, 2016).

\section{RESULTADOS E DISCUSSÃO}

A partir do resumo da análise de variância (Tabela 2) verifica-se que a porcentagem de emergência, o índice de velocidade de emergência, o tempo médio de emergência, velocidade média de emergência, altura de plântulas, comprimento de raiz e a massa seca da raiz apresentaram efeito significativo a $1 \%$ de probabilidade, onde foram influenciadas pelos fatores de água de irrigação, já a massa seca da parte aérea não foi significativo.

Para o fator substrato, apenas a massa seca da raiz sofreu efeito de variação a $5 \%$ de probabilidade. Enquanto a interação entre salinidade e substrato, apenas o comprimento da raiz foi significativo $(\mathrm{p}<0,05)$, já as demais variáveis não apresentaram influência significativa $(\mathrm{p}>0,05)$.

Tabela 2. Resumo da análise de variância e médias para a porcentagem de emergência (PE), índice de velocidade de emergência (IVE), tempo médio de emergência (TME) e velocidade média de emergência (VME), altura de plântulas (AP), comprimento da raiz (CR), massa seca da parte aérea (MSPA), massa seca da raiz (MSR).

\begin{tabular}{cccccccccc}
\hline \multirow{2}{*}{ FV } & \multirow{2}{*}{ GL } & \multicolumn{7}{c}{ Quadrado Médio } \\
\cline { 3 - 10 } & & PE & IVE & TME & VME & AP & CR & MSPA & MSR \\
\hline A & 1 & $3840,00^{* *}$ & $2,18^{* *}$ & $11,44^{* *}$ & $0,00646^{* *}$ & $580,07^{* *}$ & $5,85^{* *}$ & $0,00004^{\mathrm{ns}}$ & $0,013^{* *}$ \\
$\mathrm{~S}$ & 2 & $6303.33^{* *}$ & $0,59^{* *}$ & $1,72^{* *}$ & $0,00106^{* *}$ & $37,94^{* *}$ & $5,46^{* *}$ & $0,0166^{* *}$ & $0,0038^{*}$ \\
$\mathrm{~A} \times \mathrm{S}$ & 2 & $910,00^{\mathrm{ns}}$ & $0,09^{\mathrm{ns}}$ & $0,25^{\mathrm{ns}}$ & $0,00021^{\mathrm{ns}}$ & $1,88^{\mathrm{ns}}$ & $1,85^{*}$ & $0,00157^{\mathrm{ns}}$ & $0,00017^{\mathrm{ns}}$ \\
Trat & 5 & $11053,33^{* *}$ & $0,71^{* *}$ & $3,08^{* *}$ & $0,0018^{* *}$ & $131,94 * *$ & $4,09^{* *}$ & $0,00727^{* *}$ & $0,0042^{* *}$ \\
Res & 54 & 9120 & 0,03 & 0,17 & 0,00009 & 1,22 & 0,54 & 0,0015 & 0,00104 \\
\hline $\mathrm{CV}(\%)$ & - & 18,74 & 18,52 & 6,3 & 6,1 & 14,08 & 16,65 & 26,8 & 74,25 \\
\hline
\end{tabular}

FV: fonte de variação; GL: grau de liberdade; *: Significativo pelo teste F (p<0,05); **: Significativo pelo teste de F(p<0,01); ns: não significativo; A: água; S: substrato; Trat.: tratamento; Res: resíduo; CV: coeficiente de variação.

Observa-se na (Figura 1A) que a PE foi superior quando irrigada com água de baixa salinidade a $0,8 \mathrm{dS} \mathrm{\textrm {m } ^ { - 1 }}$. Entretanto, com o aumento do nível da salinidade para 4,0 dS m 1 , houve decréscimo. Isso pode ser explicado pelo fato de que os sais podem interferem 
reduzindo o potencial hídrico da semente. Lopes e Macedo (2008) trabalhando com couve chinesa constataram que o aumento de
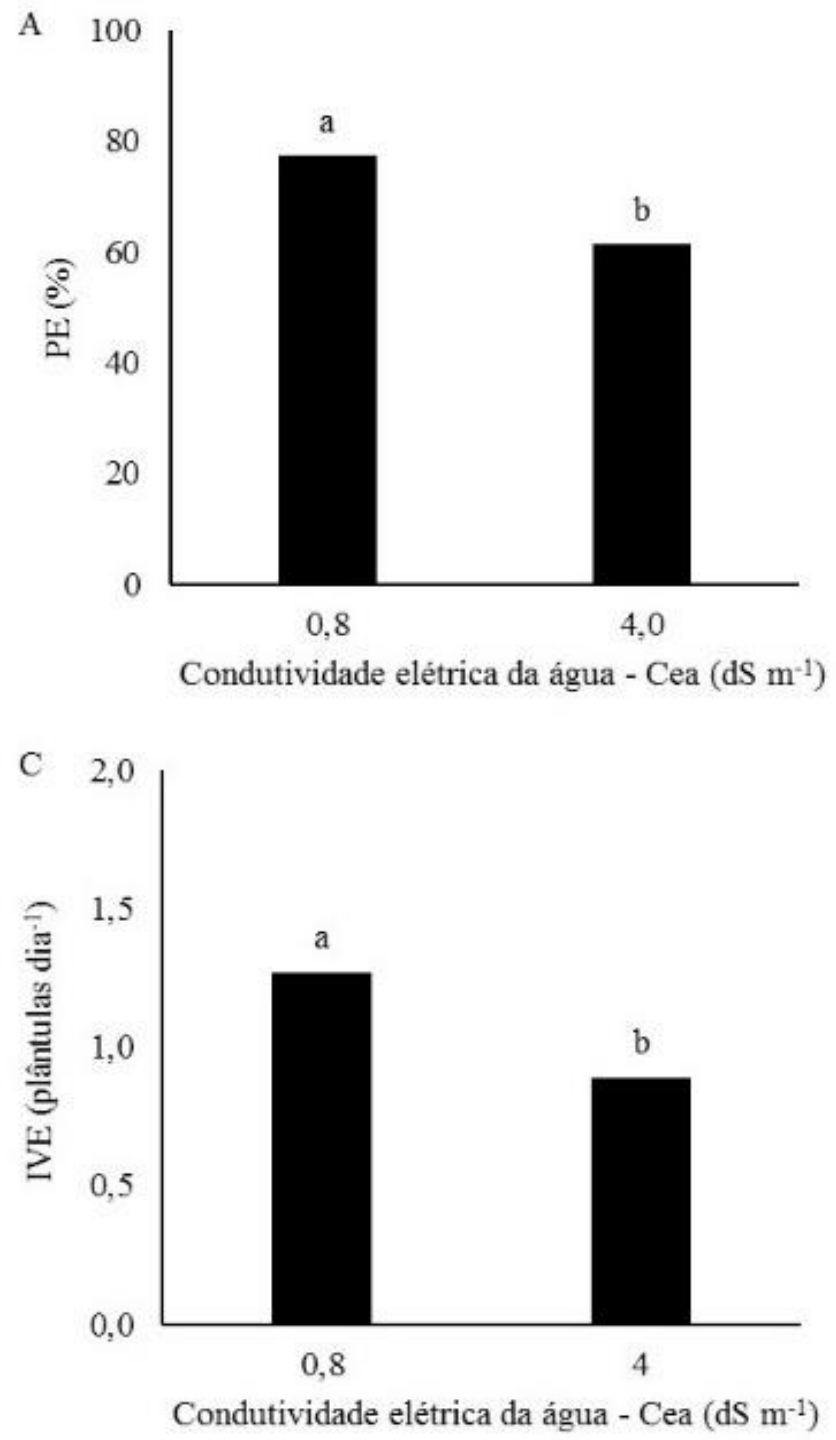

sais pode afetar a captação de água pela semente, afetando assim o potencial hídrico da semente em relação ao solo.
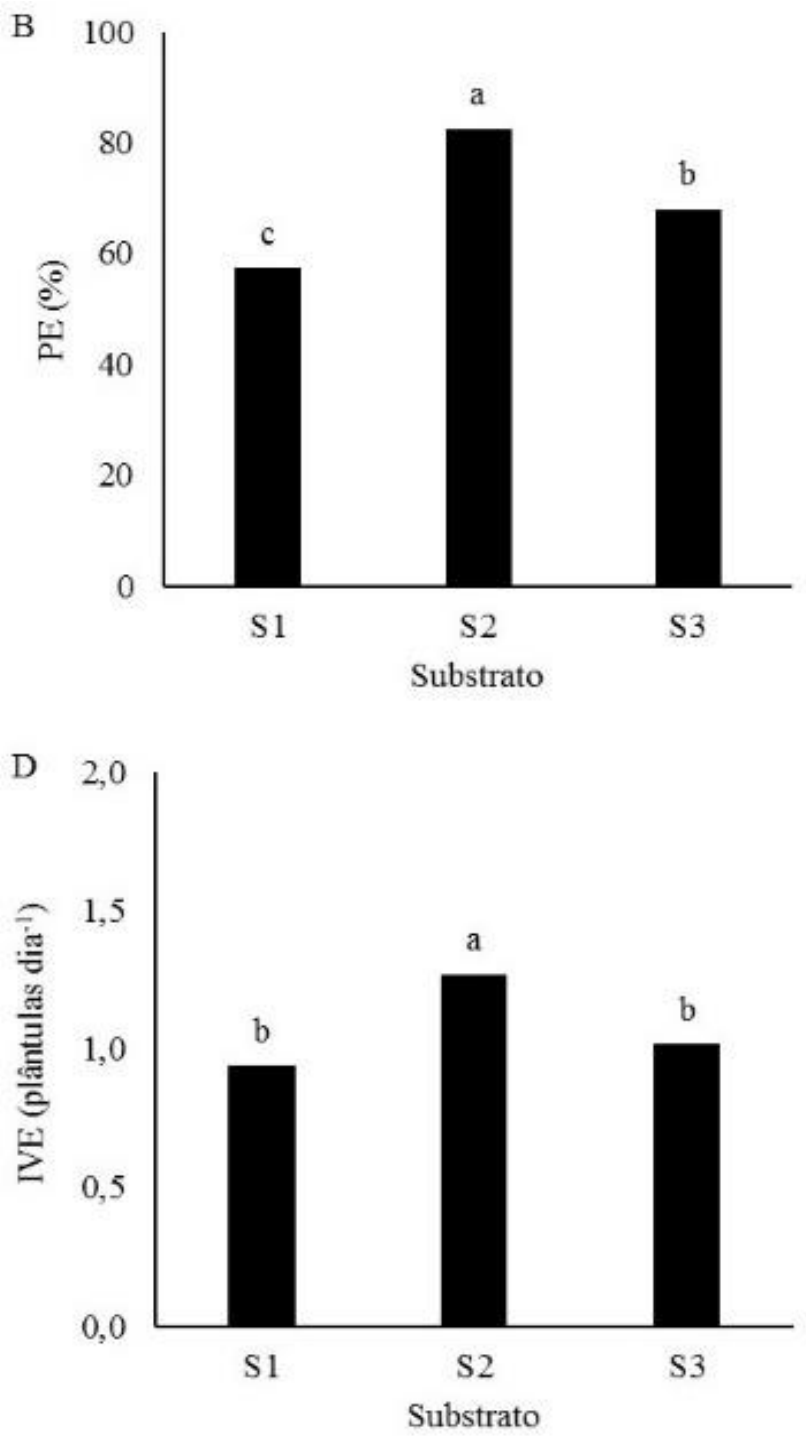

Figura 1. Porcentagem de emergência (PE), índice de velocidade de emergência (IVE) do feijão caupi, em função de diferentes águas salina $\left(0,8\right.$ e 4,0 dS.m $\left.{ }^{-1}\right)$ e três substratos (S1: Esterco Bovino, S2: Biocarvão e S3: Casca de Arroz Carbonizada).

Quanto aos substratos, na (Figura 1B), a PE obteve resultado superior em S2, diferindo estatisticamente dos demais substratos. Podendo ser justificado esse fato de que o biocarvão melhora os atributos químicos e físicos, tais como, a porosidade, além de retenção de água e nutrientes como potássio $(\mathrm{K})$ e fósforo $(\mathrm{P})$ e pode proporcionar a troca de cátion (CTC). Van Zwieten et al. (2010) descreve que o biocarvão pode modificar o $\mathrm{pH}$ do solo, por apresentar teores de nutrientes como magnésio $(\mathrm{Mg})$ e carbonato de cálcio $\left(\mathrm{CaCO}_{3}\right)$.

Foi observado redução no índice de velocidade de emergência (IVE) com salinidade a 4,0 dS m $\mathrm{m}^{-1}$ (Figura 1C). Essa queda no valor do IVE pode estar relacionada com o potencial osmótico, ocasionando dificuldade de absorção de água pela plântula. Trabalhos realizados por Coelho et al. (2017) 
avaliando a germinação e desenvolvimento inicial de variedades de feijão caupi submetidos em diferentes concentrações salinas, demostraram decréscimos semelhantes para o IVE em função do aumento da concentração salina.

Em solos salinos, os sais solúveis na solução do solo aumentam as forças de retenção de água devido ao efeito osmótico, ocorrendo assim redução na absorção de água pela planta (DIAS et al. 2016). Deste modo, os sais solúveis em grande quantidade podem atingir a planta de maneira que ela não possa ser capaz de absorver água mesmo estando em um meio úmido favorável para a absorção. Em caso de estresse osmótico, a embebição é comprometida pela redução do potencial hídrico e o crescimento da plântula é afetado pela diminuição da expansão e do alongamento celular (MOTERLE et al., 2008).

Quanto aos valores dos substratos na (Figura 1D), observa-se que o IVE quanto submetido ao S2 apresenta resultados superiores em relação ao S3 e S1, respectivamente. Isso pode estar relacionado com a capacidade do biocarvão reter nutrientes junto ao solo e melhorar a sua fertilidade. Petter et al. (2010) afirmam que o biocarvão contribui com a propriedade física, porosidade e densidade do solo. Característica que pode beneficiar as leguminosas, estimulando a fixação biológica de nitrogênio (FBN), particularmente sob condições limitantes de $\mathrm{N}$ no solo (RONDON et al. 2007).

Verifica-se que a concentração salina de 4,0 dS m$~^{-1}$ na água de irrigação, influenciou o tempo médio de emergência (TME), havendo acréscimo de dias na emergência de plântulas (Figura 2A). Resultados semelhantes foram encontrados por Albuquerque et al. (2016) trabalhando com pepino sob estresse salino ao detectarem que a salinidade afetou o índice de emergência das plântulas. Taiz e Zaiger (2013) alegam que com o aumento da salinidade, o desenvolvimento da plântula é afetado devido ao efeito osmótico, afetando a embebição e seu estabelecimento. Já o acúmulo de íons como $\mathrm{Na}^{+}$e $\mathrm{Cl}^{-}$em concentrações tóxicas podem afetar processos fisiológicos e metabólicos dos tecidos embrionários (COELHO et al. 2017). 

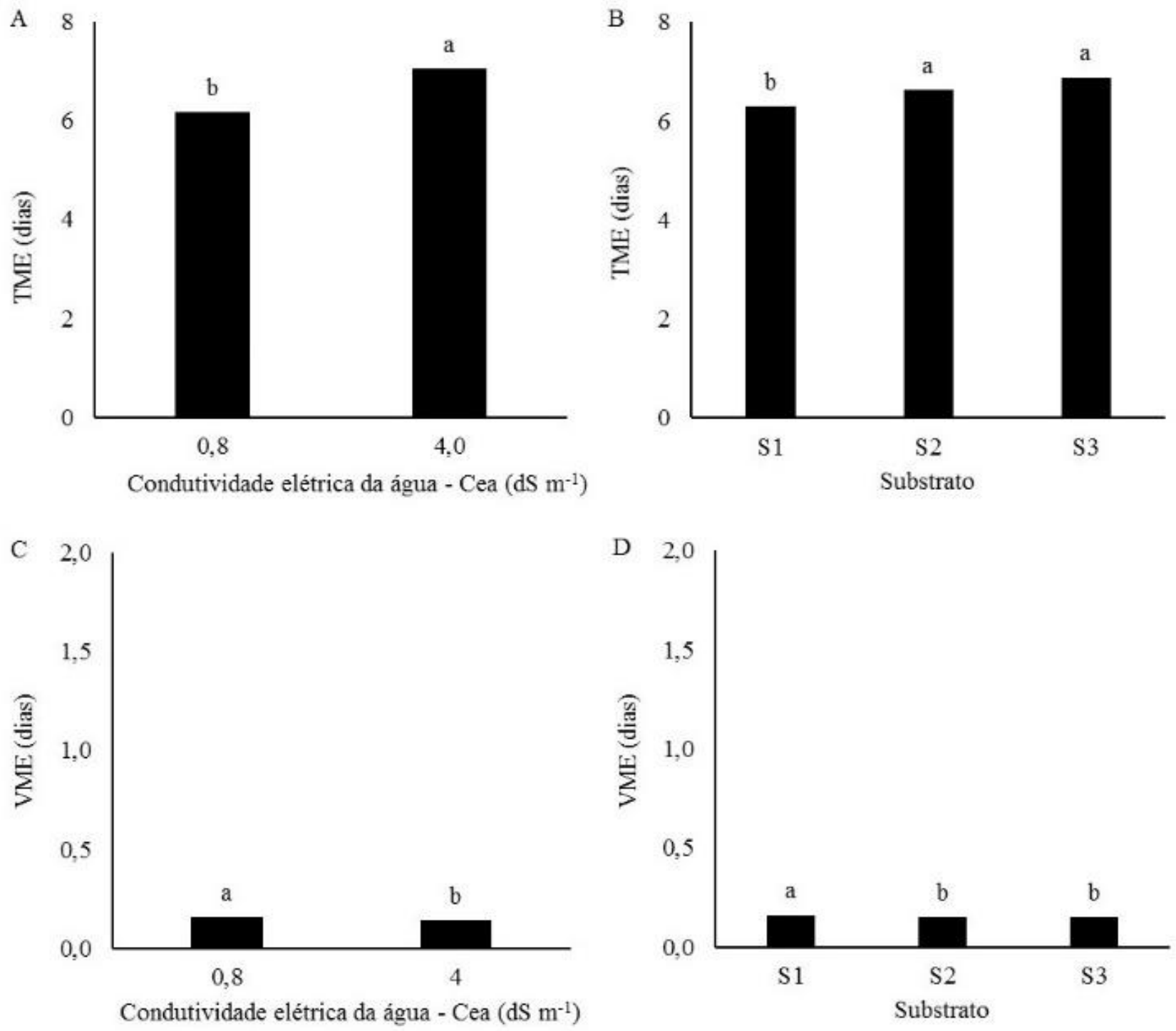

Figura 2. Tempo médio de emergência (TME), velocidade média de emergência (VME) do feijão caupi, em função de diferentes águas salina $\left(0,8\right.$ e 4,0 dS.m $\left.{ }^{-1}\right)$ e três substratos ( $\mathrm{S} 1$ : Esterco Bovino, S2: Biocarvão e S3: Casca de Arroz Carbonizada).

Para os efeitos nos substratos (Figura 2B), observa-se que no S2 e S3 não diferiram entre si, nos quais o TME amentou. Rota e Pauletti (2008) afirmam que esses valores podem ser explicados pelo aumento do $\mathrm{pH}$ no substrato, devido a um resultante aumento da porcentagem de sódio trocável (PST). Com isso, podendo causar desequilíbrio fisiológico na cultura (KÄMPF, 2000).

Quanto a velocidade média de emergência (VME) se observa que houve redução quando irrigado com água de irrigação a 4,0 dS m $\mathrm{m}^{-1}$ (Figura 2C). Este comportamento pode estar relacionado com a redução do potencial osmótico, ocasionando limitações na quantidade de água absorvida pela plântula. Limitando a embebição da semente e consequentemente a emergência das plântulas (TAIZ e ZAIGER, 2013). Bertagnolli et al. (2014), alegam que a deterioração da semente causada pelas alterações no metabolismo, juntamente com a susceptibilidade à salinidade, acarreta a perda na capacidade de germinação e posteriormente no crescimento da planta.

Em relação aos substratos (Figura 2D), se observa que para VME o S1 obteve o maior índice, sendo superior os demais substratos, 
enquanto os substratos $\mathrm{S} 2$ e $\mathrm{S} 3$ tiveram redução similares. Assim como no TME, esses resultados podem ser atribuídos a fatores como o desequilíbrio fisiológico na cultura (KÄMPF, 2000), com variações ou aumento do pH com adição dos substratos (ROTA; PAULETTI, 2008).

A altura da plântula (AP) foi reduzida quando irrigada com a água de salinidade a 4,0 $\mathrm{dS} \mathrm{m}{ }^{-1}$ (Figura 3A), podendo ser justificado pelo fato de que com a água de irrigação a 4,0 $\mathrm{dS} \mathrm{m}^{-1}$, pode afetar os processos fisiológicos da plântula, além de prejudicar a absorção de nutrientes.

Trabalho realizado com feijão por Lima et al., (2007) demostraram redução no crescimento da planta com água de irrigação
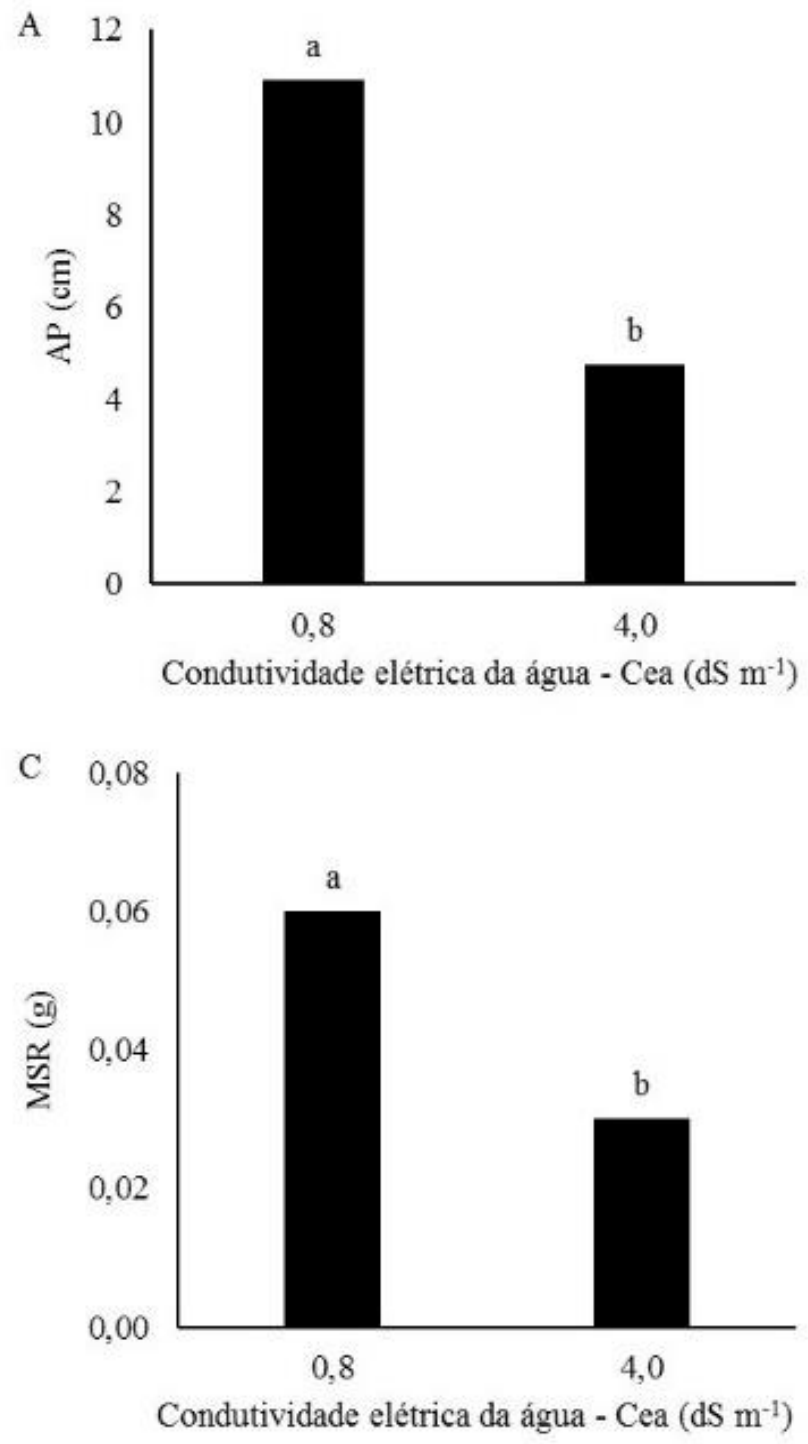

de alta salinidade. Esse comportamento se deve as altas concentrações de sais de sódio que interagem negativamente na fisiologia das plantas (TAIZ; ZEIGER, 2013).

Ao observar a (Figura 3B), a altura da plântula no substrato $\mathrm{S} 1$ os valores médios foram superiores em relação aos demais substratos (S2 e S3). Esses resultados podem ser explicados pela razão de maior presença de nutrientes e matéria orgânica, principalmente do nitrogênio, favorecendo assim, um melhor desenvolvimento da cultura. $\mathrm{O}$ esterco bovino segundo Tejada et al. (2008) proporciona ao solo nitrogênio, além do potencial de mineralização disponibilizando nutrientes para as culturas e influenciando na temperatura do substrato.
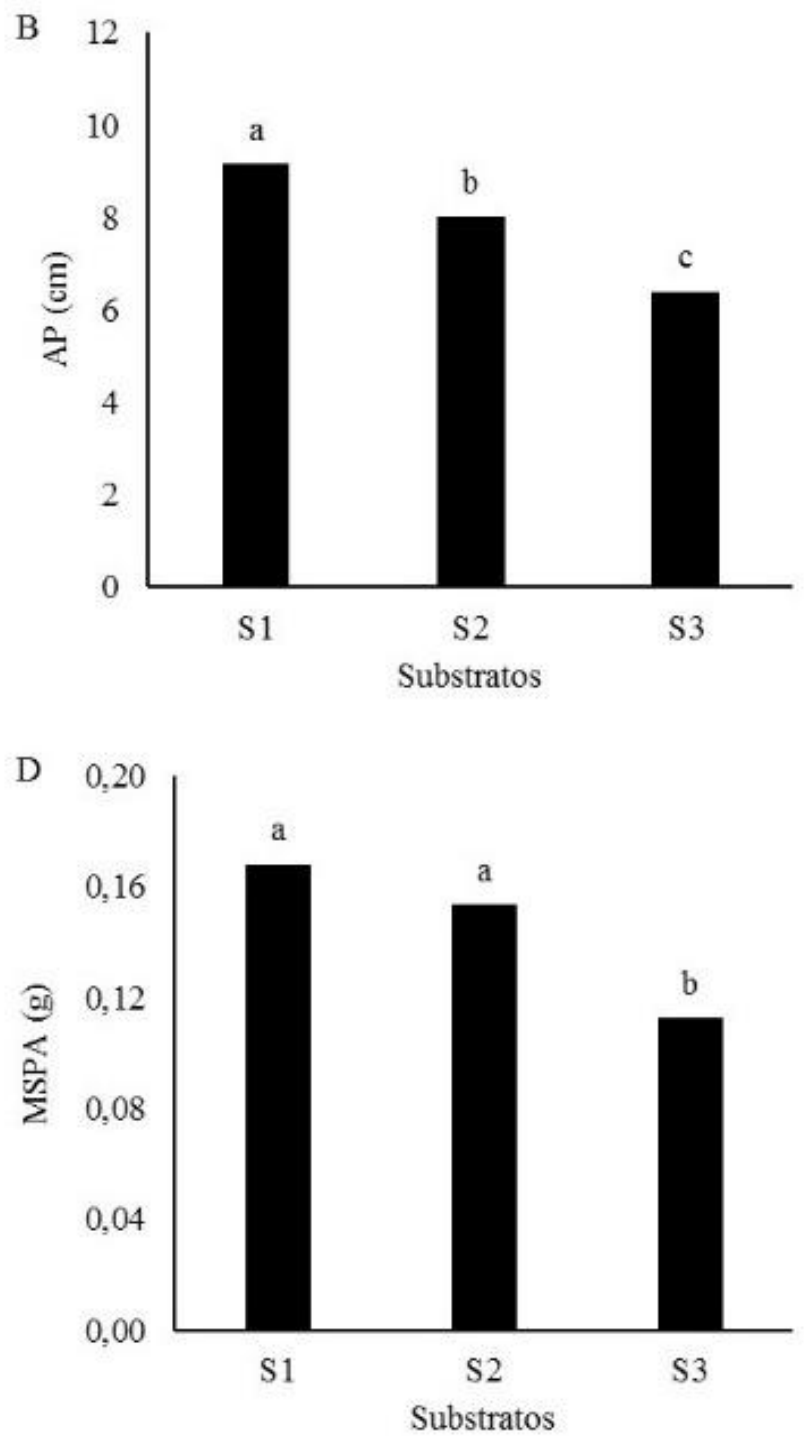


\section{EMERGÊNCIA E CRESCIMENTO DE PLÂNTULAS DE FEIJÃO-CAUPI EM SUBSTRATOS IRRIGADAS} COM ÁGUA SALINA

Figura 3. Altura da plântula (AP), massa seca da parte aérea, (MSPA), massa seca da raiz (MSR) do feijão caupi nove dias após a semeadura em função de diferentes águas salina $\left(0,8\right.$ e 4,0 dS.m $\left.{ }^{-1}\right) \mathrm{e}$ três substratos ( $\mathrm{S} 1=$ Esterco Bovino, $\mathrm{S} 2=$ Biocarvão e S3= Casca de Arroz Carbonizada).

Ao analisar a massa seca da raiz na (Figura 3C), observa-se que o aumento de nível da salinidade da água de irrigação a 4,0 $\mathrm{dS} \mathrm{m} \mathrm{m}^{-1}$, obteve redução na massa radicular da cultura. Este resultado pode estar relacionado a inibição do crescimento do sistema radicular, ocasionado pela presença de sais no substrato, podendo ter alterações assim no potencial osmótico e a toxidez. Uma vez que o sistema radicular está diretamente em contato ao meio aquoso do solo onde está o acúmulo de sais, sendo as raízes uma das partes mais prejudicadas na cultura (SOUSA et al., 2014).

Trabalhos realizados por Lopes et al. (2017) com meloeiro utilizando água salina e por Lima et al. (2007) com feijão submetido a irrigação com solução salina, obtiveram resultados semelhantes quando irrigados com água de maior salinidade obtendo redução da massa seca da raiz. Almeida et al, (2012), obtiveram resultados negativos avaliando plântula do feijão caupi com o aumento da salinidade na água de irrigação. Isso pode estar relacionado ao desequilíbrio fisiológico, bioquímico e toxicidade, que resultam em diminuição da respiração, da expansão radicular, da absorção de água e da fixação de $\mathrm{CO}_{2}$ (WILLADINO et al., 2011).

Já para a variável matéria seca da parte aérea (Figura 3D), aos substratos $\mathrm{S} 1$ e $\mathrm{S} 2$ não diferenciaram estatisticamente entre si, obtendo superioridade em relação ao S3. Estes resultados corroboram com Tejada et al. (2008) que o esterco bovino pode proporcionar melhor retenção de água e nutrientes, como nitrogênio no caso do S1. E potássio e fósforo no $\mathrm{S} 2$, melhorando a propriedade química do substrato.

Desta forma, na (Tabela 3) o S3 apresentou significância, reduzindo o comprimento da raiz quando irrigado com água de 4,0 dS.m ${ }^{-1}$. Trabalhando com feijão caupi sobre estresse salino, Almeida et al. (2012) encontrou redução no comprimento da raiz de acordo com o aumento do nível de salinidade da água de irrigação. Os efeitos da salinização sobre as plantas podem ser causados pela dificuldade de absorção de água, toxicidade de íons específicos e pela interferência dos sais nos processos fisiológicos (efeitos indiretos) reduzindo o crescimento e o desenvolvimento das plantas (DIAS; BLANCO, 2010).

Tabela 3. Comprimento da raiz $(\mathrm{CR}, \mathrm{cm})$, de plântulas de feijão sobre o efeito de dois níveis de água salina $\left(0,8\right.$ e $\left.4,0 \mathrm{dS} . \mathrm{m}^{-1}\right)$ e em diferentes substratos obtidas aos nove dias após a emergência.

\begin{tabular}{cccc}
\hline \multirow{2}{*}{ Águas } & \multicolumn{3}{c}{ Substratos } \\
\cline { 2 - 4 } & EB & BC & CAC \\
\hline $0,8 \mathrm{dS} \mathrm{m}^{-1}$ & $5,05 \mathrm{aA}$ & $4,57 \mathrm{aA}$ & $4,65 \mathrm{aA}$ \\
$4,0 \mathrm{dS} \mathrm{m}^{-1}$ & $5,01 \mathrm{aA}$ & $4,01 \mathrm{aB}$ & $3,39 \mathrm{bB}$ \\
\hline
\end{tabular}

Médias seguidas pela mesma letra minúsculas nas colunas e maiúsculas nas linhas, não diferem entre si pelo teste de Tukey $(\mathrm{p}<0,05)$. Substratos EB= areia, arisco e esterco bovino; $\mathrm{BC}=$ areia, arisco e biocarvão; CAC: areia, arisco e casca de arroz carbonizada, com proporções de (1:1:1) para ambos os substratos.

Quanto ao resultado da água de irrigação a $0,8 \mathrm{dS} \mathrm{m}^{-1}$ nos três substratos não foi verificado diferença. Entretanto, para água de irrigação a 4,0 dS m m $^{-1}$ os substratos $\mathrm{S} 2$ e S3 apresentaram resultados significativos. Segundo Ribeiro et al. (2008) esses resultados estão relacionados com o aumento da salinidade na água de irrigação, uma vez que a pressão osmótica na solução do solo aumenta a força de retenção de água, reduzindo assim a disponibilidade de água para a planta, que mesmo em solos úmidos será incapaz de 
absorver água, não tendo forças para exceder essa pressão osmótica.

\section{CONCLUSÕES}

A cultivar BRS Tumucumaque apresentou intolerância a água de irrigação com salinidade igual ou superior a $4 \mathrm{dS} \mathrm{m}^{-1}$, que limitou sua emergência.

O substrato composto por areia + arisco + esterco bovino (1:1:1), proporciona melhor desenvolvimento inicial as plântulas de feijão, uma vez que foi superior aos demais substratos analisados quanto as variáveis, altura das plântulas, comprimento da raiz, massa seca da parte aérea, massa seca da raiz e velocidade média de emergência.

\section{REFERÊNCIAS BIBLIOGRÁFICAS}

ALBUQUERQUE, J. R. T.; Sá, F. V. S.; OLIVEIRA, F. A.; PAIVA, E. P.; ARAÚJO, E. B. G.; SOUTO, L. S. Crescimento inicial e tolerância de cultivares de pepino sob estresse salino. Revista Brasileira de Agricultura Irrigada, [s.1.], v. 10, n. 2, p.486-495, 2016. INOVAGRI.

http://dx.doi.org/10.7127/rbai.v10n200355.

ALMEIDA, W. S.; FERNANDES, F. R. B.; BERTINI, C. H. C. M.; PINHEIRO, M. S.; TEÓFILO, E. M. Emergência e vigor de plântulas de genótipos de feijão-caupi sob estresse salino. Revista Brasileira de Engenharia Agrícola e Ambiental, v. 16, n. 10, p.1047-1054, 2012.

BERTAGNOLLI, C. M.; CUNHA, C. S. M.; MENEZES, S. M.; MORAES, D. M.; LOPES, N. F.; ABREU, C. M. Qualidade fisiológica e composição química de sementes de soja submetidas ao estresse salino. Revista Brasileira de Agrociência, v.10, n.3, p.287291, 2004.

COELHO, D. S.; SILVA, J. A. B.; NASCIMENTO, R. L.; COSTA, J. D. S.; SEABRA, T. X. Germinação e crescimento inicial de variedades de feijão caupi submetidas a diferentes concentrações salinas.

Revista Verde de Agroecologia e Desenvolvimento Sustentável, v. 12, n. 2, p.261-266, 2017.

DIAS, N. S.; BLANCO, F. F.; SOUZA, E. R.; FERREIRA, J. F. S.; NETO, O. N. S.; QUEIRZO, Í. Efeitos dos sais na planta e tolerância das culturas à salinidade. In: GHEYI, H. R.; DIAS, N. S.; LACERDA, C. F. Manejo da salinidade na agricultura: Estudos básicos e aplicados. 2. ed. Fortaleza: Inctsal, 2016. Cap. 11, p. 151-152.

DIAS, N. S; BLANCO, F. F. Efeitos dos sais no solo e na planta. In: GHEYI, H. R.; DIAS, N. S.; LACERDA, C. F. Manejo da salinidade na agricultura: Estudos básicos e aplicados. 1. ed. Fortaleza: Inctsal, 2010. Cap.9 p.129-141.

GRABER, E. R.; MELLER HAREL, Y.; KOLTON, M.; CYTRYN, E.; SILBER, A.; RAV DAVID, D.; TSECHANSKY, L.; BORENSHTEIN, M.; ELAD, Y. Biochar impact on development and productivity of pepper and tomato grown in fertigated soilless media. Plant and soil, v. 337, n. 1-2, p. 481496, 2010.

IPECE, Instituto de Pesquisa e Estratégia Econômica do Ceará, Secretaria do Planejamento e Gestão. Perfil municipal 2017 Redenção. 2017. Disponível em: <https://www.ipece.ce.gov.br/wpcontent/uploads/sites/45/2018/09/Redencao_2 017.pdf>. Acesso em: 03 abr. 2019.

KÄMPF, A. N. Produção comercial de plantas ornamentais. Guaíba: Agropecuária, 2000. 254 p.

LABOURIAU, L. G.; VALADARES, M. E. $B$. On the germination of seeds Calotropis procera (Ait.) Ait.f. Anais da Academia Brasileira de Ciências, v. 48, n. 2, p. 263284, 1976.

LEITE, J. V. Q.; OLIVEIRA, W. J.; SOUZA, E. R.; SANTOS, D. P.; SANTOS, C. S. Efeito do estresse salino e da composição iônica da água de irrigação sobre variáveis morfofisiológicas do feijão caupi. Revista 
Brasileira de Agricultura Irrigada, v.11, n.6, p. 1825 - 1833, 2017.

LIMA, C. J. G. S.; OLIVEIRA, F. D. A.; MEDEIROS, J. D.; OLIVEIRA, M. D.; ALMEIDA JÚNIOR, A. D. Resposta do feijão caupi a salinidade da água de irrigação. Revista Verde, v. 2, n. 2, p.79-86, 2007.

LOPES, J. C.; MACEDO, C. M. P. Germinação de sementes de couve chinesa sob influência do teor de água, substrato e estresse salino. Revista Brasileira de Sementes, v. 30, n. 3, p. 79-85, 2008.

LOPES, M. Â. C.; MUNIZ, R. V. S.; ALVES, S. S. V.; FERREIRA, A. C.; SÁ, F. V. S.; SILVA, L. A. Água salina e substratos no crescimento inicial do meloeiro. Irriga, v. 22, n. $3, \quad$ p.469-484, 2017. http://dx.doi.org/10.15809/irriga.2017v22n3p4 69-484.

MAGUIRE, J.D. Speed of germination-aid in and evaluation for seedling emergence and vigour. Crop Science, Madson, v.2, n.1, p.176-177, 1962.

MOTERLE, L. M.; SCAPIM, C. A.; BRACCINI, A. L.; RODOVALHO, M. A.; BARRETO, R. R. Influência do estresse hídrico sobre o desempenho fisiológico de sementes de híbridos simples de milho-pipoca. Ciência e Agrotecnologia, v.32, n.6, p.18101817, 2008.

NAKAGAWA, J. Testes de vigor baseados no desempenho das plântulas. In: KRZYZANOWSKI， F.C.; VIEIRA， R.D.; FRANÇA NETO, J.B. (Eds.). Vigor de sementes: conceitos e testes. Londrina: ABRATES, cap. 2, p.2-24, 1999.

NOVAK, J. M.; LIMA, I.; XING, B.; GASKIN, J. W.; STEINER, C.; DAS, K.; AHMEDNA, M.; REHRAH, D.; WATTS, D. W.; BUSSCHER, W. J. Characterization of designer biochar produced at different temperatures and their effects on a loamy sand. Annals of Environmental Science, v. 3, n. 1, p. 2, 2009.

PETTER, F. A. Biomassa carbonizada como condicionador de solo: aspectos agronômicos e ambientais do seu uso em solos de cerrado. 2010. 130 f. Tese (Doutorado em Agronomia) - Universidade Federal de Goiás.

RHOADES, J. D.; KANDIAH, A.; MASHALI, A. M. Uso de águas salinas para produção agrícola. Campina Grande: UFPB, 2000. 117 p. (Estudos FAO Irrigação e Drenagem, 48).

RIBEIRO, M. C. C.; BARROS, N. M. S.; BARROS JÚNIOR, A. P.; SILVEIRA, L. M. Tolerância do sabiá (Mimosa caesalpiniifolia benth) à salinidade durante a germinação e o desenvolvimento de plântulas, Revista Caatinga, v.21, n.5, p.123-126, 2008.

RONDON, M.; LEHMANN, J.; RAMÍREZ, J.; HURTADO, M. Biological nitrogen fixation by common beans (Phaseolus vulgaris L.) increases with bio-char additions. Biology and fertility of soils, v. 43, n. 6, p. 699-708, 2007.

ROTA, L. D.; PAULETTI, G. F. (Ed.). Efeito da adição de casca de arroz em substrato comercial a base de turfa na produção de mudas de Viola tricolor L. Revista Brasileira de Agrociência, v. 14, n. 3-4, p.45-48, 2008.

SAIDELLES, F. L. F.; CALDEIRA, M. V. W.; SCHIRMER, W. N.; SPERANDIO, H. V. Casca de arroz carbonizada como substrato para produção de mudas de tamboril-da-mata e garapeira. Semina: Ciências Agrárias, v. 30, n. 4, p.1173-1186, 2009.

SILVA, F. A. S.; AZEVEDO, C. A. V. The Assistat Software Version 7.7 and its use in the analysis of experimental data. African Journal of Agricultural Research, v.11, n.39, p.3733-3740, 2016. DOI: 10.5897/AJAR2016.11522 
SILVA, F. D.; LACERDA, C. D.; NEVES, A. L. R.; SOUSA, G. D.; SOUSA, C. D.; FERREIRA, F. J. Irrigação com águas salinas e uso de biofertilizante bovino nas trocas gasosas e produtividade de feijão-de-corda. Irriga, v. 18, n. 2, p. 304-317, 2013.

SILVA, F. E. O.; MARACAJÁ, P. B.; MEDEIROS, J. F.; OLIVEIRA, F. D. A.; OLIVEIRA, M. K. T. Desenvolvimento vegetativo do feijão caupi irrigado com água salina em casa de vegetação. Revista Caatinga, v. 22, n. 3, p. 152-155, 2009.

SILVA, R. P.; PEIXOTO, J.R.; JUNQUEIRA, N.T.V. Influência de diversos substratos no desenvolvimento de mudas de maracujazeiro azedo (Passiflora edulis Sims flavicarpa DEG). Revista Brasileira de Fruticultura, v.23, n.2, p.377-381, 2001.

SOUSA, G. G.; ARAÚJO VIANA, T. V.; LACERDA, C. F.; AZEVEDO, B. M.; SILVA, G. L.; COSTA, F. R. B. Estresse salino em plantas de feijão-caupi em solo com fertilizantes orgânicos.

Revista

Agro@mbiente On-line, v. 8, n. 3, p. 359367, 2014.

TAIZ, L.; ZEIGER, E. Fisiologia vegetal. Porto Alegre: Artmed, 5.ed. 2013. 918p.

TEJADA, M.; GONZALEZ, J, L.; GARCIAMARTINEZ, A. M.; PARRADO, J. Effects of diferente green manures on soil biological properties and maize yield. Bioresource technology, v.99, p. 1758-1767, 2008.

VAN ZWIETEN, L.; KIMBER, S.; MORRIS, S.; CHAN, K.; DOWNIE, A.; RUST, J.; JOSEPH, S.; COWIE, A. Effects of biochar from slow pyrolysis of papermill waste on agronomic performance and soil fertility. Plant and soil, v. 327, n. 1-2, p. 235-246, 2010 .

WILLADINO, L.; GOMES, E. W. F.; SILVA, E. F. F.; MARTINS, L. S. S.; CAMARA, T. R. Efeito do estresse salino em genótipos tetraplóides de bananeira. Revista Brasileira de Engenharia Agrícola e Ambiental, v. 15, n. 1, p. 53-59, 2011. 